\title{
Ten Steps Qualitative Modelling: Development and Validation of Conceptual Institutional-Social- Ecological Model of Public Open Space (POS) Governance and Quality
}

\author{
Gabriel Hoh Teck Ling ${ }^{1, *}$ and Pau Chung Leng ${ }^{2}$ \\ 1 Faculty of Built Environment \& Surveying (Urban and Regional Planning), Universiti Teknologi Malaysia, \\ Johor Bahru 81310, Malaysia \\ 2 Faculty of Built Environment \& Surveying (Architecture), Universiti Teknologi Malaysia, \\ Johor Bahru 81310, Malaysia; pcleng2@utm.my \\ * Correspondence: gabriel.ling@utm.my; Tel.: +60-1-461-99363
}

Received: 30 July 2018; Accepted: 19 September 2018; Published: 21 September 2018

\begin{abstract}
Compared to the literature on quantitative and statistical modelling, there is a lack of research on qualitative environmental-related modelling, which focuses on a conceptual-theory-based model. Therefore, this paper attempts to formulate a qualitative institutional-social-ecological model, by showcasing how the 10 steps modelling is relevant and is applied to the institutional-property-rights model of neighbourhood residential commons. Using an instance from one case study (i.e., Sabah, Malaysia), a conceptual problem-solution model describing local property-rights system tragedies of public open space (POS) governance and quality, and the emergence of self-governing collective action was demonstrated. Methodologically, the modelling procedures were specified as a 10-step process, starting with setting the objectives of the model and concluding with the validation of suitability and usefulness of the model. The validation was conducted using the experts' opinion, via the semi-structured interviews with five public officials. With slight necessary amendments, the model was proven practical, useful, flexible, reliable and valid in serving its purposes in understanding and predicting the effects of local property-rights system tragedies on POS commons dilemmas, and the subsequent emergence and necessity of a self-governing solution. This local model provides policy insights to the local public officials, which facilitate their institutional-social-ecological decision-making process that helps improve local POS governance and quality.
\end{abstract}

Keywords: institutional-social-ecological model; 10-step modelling; conceptual theory-based problem-solution model; qualitative model development and validation; property-rights system; transaction costs; neighbourhood residential public open space (POS) quality; governance

\section{Introduction}

Beakley and Chilton [1] (p. 268) defined a model as a "simplified, idealised version of a complex system". In social science research, "Model here means theory: a system of related concepts to describe an idea or phenomenon." [2] (p. 2). As for the purpose and significance of a model, Jakeman et al. [3] posited it as "The complexity of these situations has led to model based approaches for examining their components and interactions and for predicting management outcomes". There are many modelling frameworks, protocols, and best practices available, but finding a suitable one is difficult. Their fully reported methodologies on an explicit and systematic set of procedures are little and are predominately applied in quantitative modelling. A clear, step-by-step procedural 
framework for qualitative environmental-related modelling has been less paid attention to. Against this background, this study focuses more on qualitative social-ecological system modelling. That is this local model nested few supplemental quantitative/statistical approaches within it; thus, as a whole, the model design is still called qualitative (see Forbus [4] on the qualitative mathematics, which is considered as qualitative modelling). This paper employs notable Jakeman's et al. [3] model development and validation steps. This is because Jakeman et al. [3] outlined clear ten steps modelling to explain and support resource management and use system, which is deemed relevant to this study's social-ecological governance dimension. More essentially, although this 10-step modelling is originally and primarily crafted for quantitative modelling, it can also be sufficiently generic and inclusive for qualitative modelling [5,6] and is applicable in environmental and economic related fields. See Jorgensen and Bendoricchio's [7] and Wainwright and Mulligan's [8] ecological and environmental modelling, and Grafton et al. [9] for economic-environmental systems. Based on our literature search, the application of the ten steps in qualitative-designed modelling is indeed very limited; therefore, such attempt is worth to be explored in this study so that it may methodologically value-add to the 10-step modelling framework, regarding its application validity and flexibility in qualitative modelling. As such, this paper attempts to test whether Jakeman's ten steps are applicable and valid in this study's qualitative modelling and showcases how these ten steps are relevant to conceptual theory-based institutional-social-ecological modelling, which is more of a qualitative design. The aforementioned social-ecological model is herein referred to as a model that comprises a system composed of organised assemblages of humans and environment in a spatially determined geophysical setting [10]. See Resilience Alliance [11], that it is "integrated systems of ecosystems and human society with reciprocal feedback and interdependence"; and Ostrom's [12,13] institutional analysis and development framework that is considered as a social-ecological system framework, which also covers governance/institutional dimension. Thus, the terms social-ecological system and institutional-social-ecological system are used interchangeably in this paper.

The focus of the study is largely confined to the development and validation the model; hence, this paper attempts to demonstrate how Jakeman's et al. 10-step framework is explicitly applied in this local qualitative institutional-social-ecological modelling, and thus its application in the study area. This paper uses the actual cases from neighbourhood residential commons of a local diverse property-rights system that mainly source from prior studies' data and findings [14,15], particularly for the development process stage of the model. That is, it should be noted that, the authors succinctly describe the key data and findings of the previous studies that are applicable to this model development, rather than discussing in-depth each methodology covering what variables and parameters are involved, their interrelationships, and how are they derived. This approach is similar to the reporting manner by Robson et al. [5]. Suffice to say, this paper contributes primarily to the validation process of modelling as the processes of empirical data collection and data analysis are mainly involved in this stage. At the same time, problem-solution institutional-social-ecological modelling, as used here, refers to modelling the property-rights system issues and transaction costs affecting public open space (POS) governance and quality issues and contributing to property-rights realignment (i.e., self-governing collective action). This type of problem-solution model covers the following: (i) Establishing the context; (ii) identifying the problems; (iii) proposing solution(s) (desirable condition); and (iv) offering an evaluation, possibly relative to competing solutions, arguments or theories [15].

\section{10-Iterative Steps for Local Institutional-Social-Ecological System Modelling}

\subsection{Define Model Purpose}

Jakeman's ten steps below are iterative that involve a trial-and-error process (Figure 1). Drawing on the local case studies (i.e., districts of Kota Kinabalu and Penampang, Sabah, Malaysia) of institutional-social-ecological dimensions, the model generally aims to provide institutional-related 
information to facilitate and improve better decision-making and prediction of stakeholders in the governance of POS. The model is based on the context of understanding and amelioration of the institutional property-rights issues and status quo of POS management and consumption. In other words, the aim or the purpose of this model is set to address the following questions: (i) Does the model adequately reflect the process of the institutional property-rights system and POS issues status quo, and its interconnections, hence its predictive and decision-making ability concerning the property-rights issues and POS governance dilemmas? And (ii) does the solution of self-governing common property regime suffice to improve the issues and in turn render better POS quality?

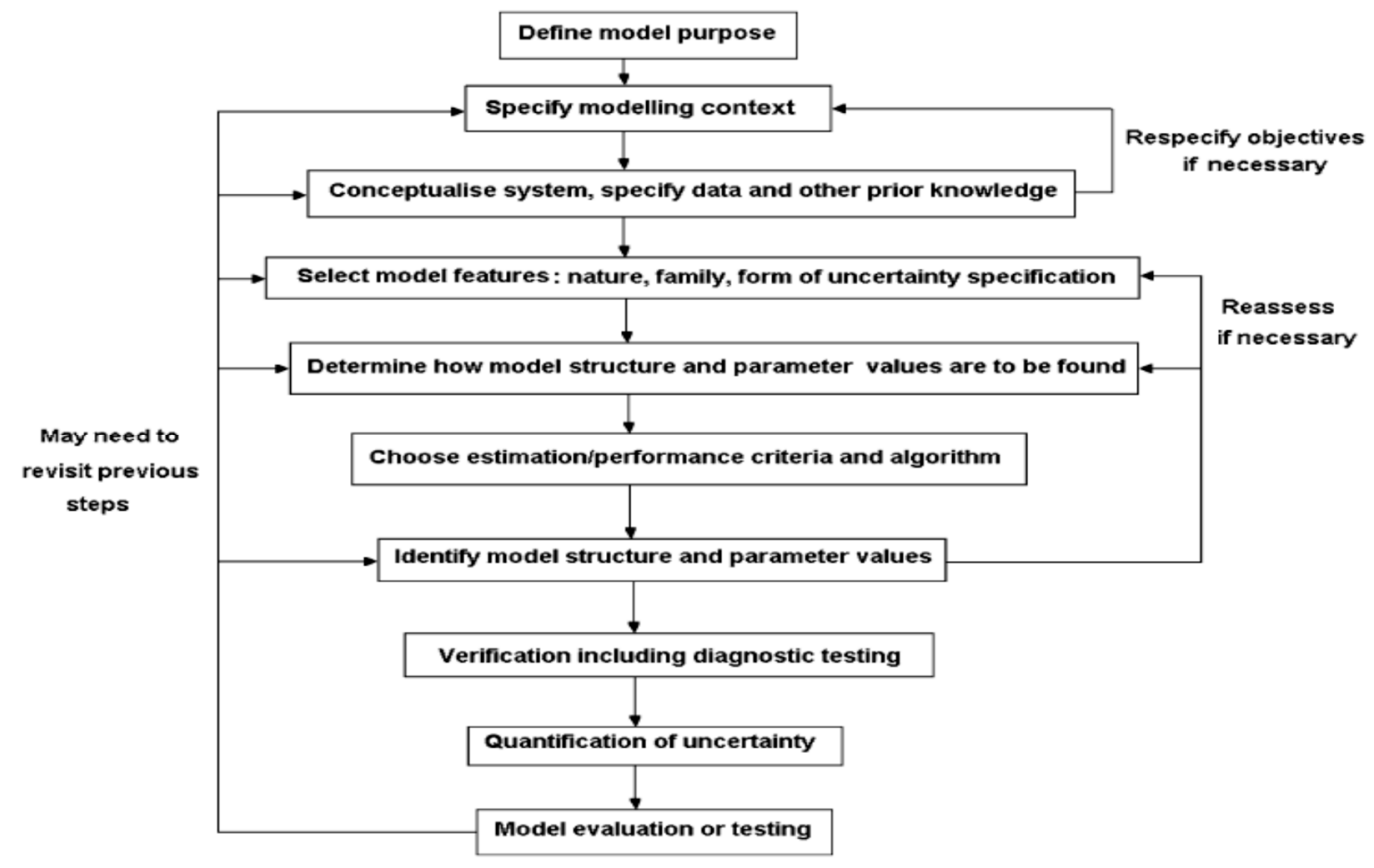

Figure 1. Iterative model, building 10 steps [3].

\subsection{Specify Modelling Context: Scope and Resources}

This step is to decide the boundary of the modelled system. There is a list of questions concerned here: (i) What are the core variables (factors/drivers) or specific issues involved in the model, which this leads to the types of results required. This model mainly covers the institutional-social-ecological behavioural dimension. The model primarily relied on an extensive dataset from a field approach. Empirical data collection was conducted using various methods (interviews, observation, questionnaires) from multiple departments and organisations (e.g., land office and local authorities), as well as from the public's perception. The development of the model also employed rigorous theoretical literature, such as Coasian's property-rights theory, Ostrom's commons and self-governing system [12], the model depiction of relationship between the institutional property-rights, transaction costs, and ecological performance. Then, (ii) what is the timescale relevant to model output? This model is more appropriate to be applied in Sabah, particularly in the districts of Kota Kinabalu and Penampang (Figure 2) with diverse practice-based property rights distributions of CL and NT POS governance (see Table 1). As this practice has been formally enforced by the Director of the Lands and Surveys Department of Kota Kinabalu (as headquarters), it applies to other districts within the entire State of Sabah. More precisely, although the existing POS governance system is deemed a de facto practice-based rights structure, the following are the key de jure systems or state laws construed to support and justify such practice of local diverse property rights system of CL and NT POS, namely the Federal Constitution, the Sabah Land Ordinance (SLO), the Town and Country Planning Ordinance (TCPO) Cap 141, the Local Government Ordinance (LGO) 1961, the Modified Torrens System, and a judicial decision of a case: Sabindo Nusantara Sdn Bhd \& Anor v 
Majlis Perbandaran Tawau \& Ors (2011) 8 MLJ 653. The land use covered in this model is residential, of which neighbourhood POS is within a 10 to 15-min walk of a user's home. For the category of land, it is mostly applied to the country lease (CL) and Native Title (NT) POS, which is located in an uptown or rural area. According to the Sabah Land Ordinance (SLO) Cap 68, Country Land and Native Land are considered as rural land as they are outside of the town area boundary. The residential use mostly falls under country land and native land. Under the country land, country lease is alienated with a title deed, but in the form of lease (not exceeding 99-year lease of tenure), and this can be owned by both non-native and natives, while native title, in a title form, is the land that can only be held by natives perpetually (no expiration of term. The usages of spaces only cover the scope of active informal spaces and regular shaped POS, including playground, basketball and badminton courts. The size or area of POS in this model is at least exceeding 0.1 acres. Finally, the model is only relevant to public or government-owned spaces, which denotes the final question, (ii) who will use the model? Sabah's institutional model is usually complex and qualitative-it is often accessible only to trained and experienced modellers, including the local and regional environmental managers, land officers and urban planners, landscapers and architects. The model was designed to be used to run scenarios that are relevant to POS governance issues related to management and consumption concerns, in which stakeholders, including public users and private suppliers or developers can be involved.

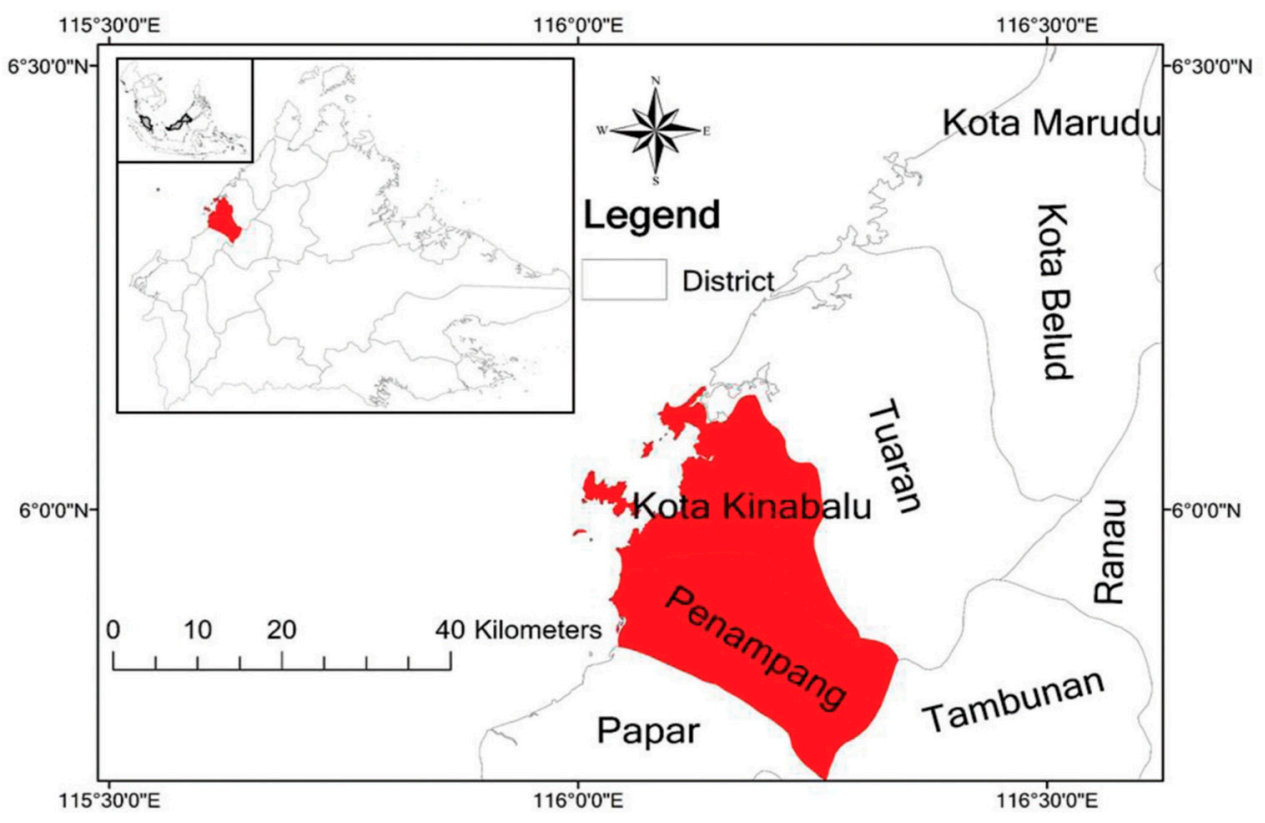

Figure 2. Map of Kota Kinabalu and Penampang districts, Sabah, Malaysia [14].

Based on Table 1, apart from the titled CL POS, with three composite stages of rights allocation, and the un-titled state-owned NT POS, which are fleshed out in Ling [15]. To summarise, both CL POS and NT POS are open for public access. Since owners either private subdivider, or ultimately local government, regardless of the interim period and transitioning period, eventually own clear access, withdrawal and management rights, they are regarded as claimants. The purpose of the table above is to essentially demonstrate the prominent diverseness and complexity of local property-rights institution in the neighbourhood POS governance. These include the issues of title deed issuance, community association presence, POS site handing over, and transfer of POS title deed that diversely determine the alignments of rights and regimes; hence, the POS governance, especially in terms of the ownership, management and utilisation rights of stakeholders. It is vital to understand whether these current institutional heterogeneities, taken as core exogenous variables, have different implications on the well-being and quality of local POS, particularly from the social-ecological behavioural interaction perspective. 
Table 1. Sabah's de facto diverse property-rights system of country lease (CL) and Native Title (NT) POS governance.

\begin{tabular}{|c|c|c|c|c|}
\hline Property-Rights System & & CL NPOS & & NT NPOS \\
\hline $\begin{array}{l}\text { Title-ship of POS (Issuance of } \\
\text { title deed) }\end{array}$ & \multicolumn{3}{|c|}{ (Title deed is granted on POS) (Involving POS site handing over and POS title deed transfer) } & (No title deed issuance on NT POS) \\
\hline \multirow{2}{*}{$\begin{array}{l}\text { Status of transfer and site } \\
\text { handing over of POS }\end{array}$} & $\begin{array}{c}\text { First phase CL POS (Before title } \\
\text { deed issuance) }\end{array}$ & $\begin{array}{l}\text { Second phase CL POS (Before } \\
\text { title deed issuance: Interim) }\end{array}$ & $\begin{array}{c}\text { Third phase CL POS (Title } \\
\text { deed issued) }\end{array}$ & \multirow[b]{2}{*}{$\begin{array}{l}\text { Surrendered POS (Without title) } \\
\text { (Without title-state land) (Needless } \\
\text { site handing over/title transfer) }\end{array}$} \\
\hline & $\begin{array}{l}\text { (Un-transferred title) (Un-handed } \\
\text { over site) (Held under owner's } \\
\text { covenant) }\end{array}$ & $\begin{array}{l}\text { (Un-transferred title) }(\text { Handed } \\
\text { over site) ('Bare Trustee') }\end{array}$ & $\begin{array}{l}\text { (Transferred title) (Handed } \\
\text { over site) }\end{array}$ & \\
\hline Land ownership & $\begin{array}{l}\text { Private/Common } \\
\text { property-developer/owners }\end{array}$ & $\begin{array}{c}\text { State property-Local } \\
\text { government (As an equitable } \\
\text { owner) }\end{array}$ & $\begin{array}{l}\text { State property-Local } \\
\text { government (As a legal } \\
\text { owner) }\end{array}$ & $\begin{array}{l}\text { State property-Local government (As } \\
\text { an equitable owner) }\end{array}$ \\
\hline $\begin{array}{l}\text { Management regime (including } \\
\text { monitoring, maintaining, } \\
\text { control, etc.) }\end{array}$ & $\begin{array}{l}\text { Private/Common } \\
\text { Property-(Developer/Co-landowner(s)) } \\
\text { (Temporary—e.g., minimum } 18 \\
\text { months) }\end{array}$ & $\begin{array}{l}\text { State property-Local } \\
\text { Government or Local } \\
\text { government + Common } \\
\text { property/community } \\
\text { association-residents } \\
\text { (registered)* }\end{array}$ & $\begin{array}{l}\text { Private/Common Property- } \\
\text { (Developer/Co-landowner(s)) } \\
\text { (Temporary—e.g., minimum } \\
18 \text { months) }\end{array}$ & $\begin{array}{l}\text { Open-access resource (without being } \\
\text { vested in Local Council) }\end{array}$ \\
\hline Positions: Bundle of rights & \multicolumn{3}{|c|}{$\begin{array}{l}\text { Claimant: Only access, use and management rights are clearly and actively possessed by subdivider(s) } \\
\text { and local government }\end{array}$} & $\begin{array}{c}\text { Authorised users: Public users with } \\
\text { use and access rights }\end{array}$ \\
\hline Access & \multicolumn{3}{|c|}{ Yes } & Yes \\
\hline Withdrawal/use & \multicolumn{3}{|c|}{ Yes } & Yes \\
\hline Management & \multicolumn{3}{|c|}{ Yes } & None \\
\hline Exclusion & \multicolumn{3}{|c|}{ None } & None \\
\hline $\begin{array}{l}\text { Alienation (e.g., POS disposal, } \\
\text { title deed transfer) }\end{array}$ & \multicolumn{3}{|c|}{ The title deed is only transferable to the local council by the private titleholder(s) } & Not transferable \\
\hline
\end{tabular}




\subsection{Conceptualisation of the System, Specification of Data and Other Prior Knowledge}

Conceptualisation refers to basic premises about the working of the system being modelled. It mainly shows how model drivers are linked to internal variables and outputs (observed responses). The conceptualisation step is essential if a model is not designed from scratch or merely a "canned" model is used. The canned model's weaknesses are detected, which can be illustrated in Gerber's et al. [17] institutional-social-ecological model as it does not provide a fuller, comprehensive view on (how) institutional rights failures emerge, and why and how they affect social-ecological opportunistic behaviour. The conceptualisation of an institutional property-rights system on POS governance has involved variety of the theories and concepts, namely neo-institutional economics, particularly property-rights (rights issues), transaction costs, commons, self-interestedness and opportunism, social (commons) dilemmas, self-governing collective action [12], club goods, and Nelson's homeownership association. The key components, data or variables that employed in this study are as follows: Characteristics of governance system and POS concept and its quality attributes (see more in Ling [15], Ling et al. [18], Ling et al. [14]; Ling et al. [19]). For the institutional property-rights structure of the local POS system, it questions whether the POS system is inflicted with property-rights issues, namely misalignment of rights, insecurity of right, incompleteness of rights, attenuation of rights, which are the resultant of title deed existence, title deed possession, community association involvement, POS title deed transfer, site POS handing over, ownership regime, bundle of rights, e.g., management right, use right, access right and alienation right.

\subsection{Selection of Model Features and Families}

Model structure specifies the links between the system's components and processes. Structural features include the functional form of interactions, and data structures used to determine relationships, spatial and temporal scales of processes and their interactions. In this local system, three types of model features were suggested and employed. The model structure includes (i) a process or theory-based model; (ii) a conceptual paradigm model (see Figure 3; and see Strauss and Corbin [20]; and Ling's [15] (p. 97) conceptual framework); and (iii) a Sustainable Development Triangle model [21]. The latter was used as the final model presentation, because of its relevancy in terms of the demonstration of interrelationships nature among the components. For example, the social and ecological dimensions here can be likened to the POS institutional and governance system, and their impacts towards the central focus (sustainability) can be equated to POS quality (see the validation stage in Section 2.10 below). The theory-process-based model is fit as the appropriate form, given the provided resources and expertise, primarily based on the agent-modelling approach. Most agents' components are more readily conceptualised in the forms of property rights and regimes, and costs and incentives issues, which include, e.g., social dilemmas and Ostrom's collective action theories. In other words, this model is used when multiple theories were involved in the local modelling. Next, the conceptual model, which is about the relationships between theories and concepts, has been selected, because it was suitable in this time institutional-social-ecological modelling, which mainly shows clear interrelationships among the components. The different yet interrelated components are local property-rights system issues and transaction-cost-based opportunistic social-POS interaction dilemmas, and Ostrom's common-property-based self-governance. Moreover, the paradigm model, similar to Ostrom's [12] social-ecological system model or institutional analysis and development framework, was adopted because it is useful for a theories application model and describes the causal-effect interrelationships effectively. More importantly, all of them can be mixed to corroborate each other so that a more complete proposed model is provided. That is, given a setting (contextual condition), the conceptual process-based model is aligned with Strauss and Corbin's [14] structure. The process or event begins with the (i) causal factor and central phenomenon-diverse local practice and property-rights issues, then the (ii) social-ecological interaction point-stakeholders' POS governance (use and management) pattern and POS commons dilemmas emergence, and lastly the (iii) consequences-the emergence of negative POS externalities and Ostrom's eight design principles. 
In short, the model, as shown in Figure 3, is to establish and explain that the diverse property rights system in Sabah, which embeds some rights issues can result in neighbourhood residential POS dilemmas and negative externalities via opportunistic and self-interest individuals' behaviour. This POS status quo consequently calls for the self-organising common-property regime as a solution.

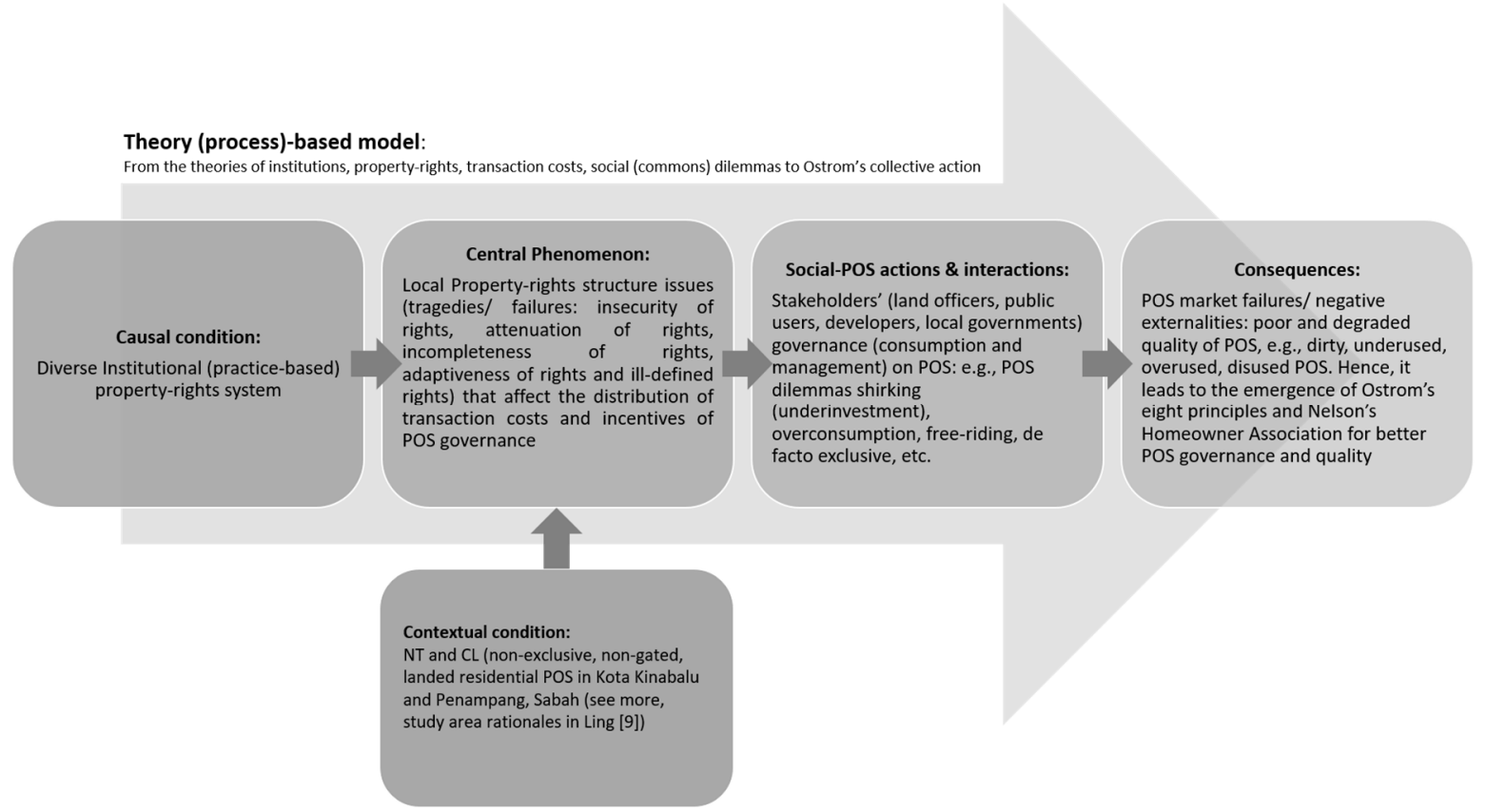

Figure 3. Conceptual problems-solution model-Combination of theory (process)-based model and paradigm model of institutional property-rights system on POS governance issues, and its solution (Adapted from Strauss and Corbin [20]; and Ling [15]).

\subsection{Determine How Model Structure and Parameter Values Are to Be Found}

The model structure includes the components sequence, flow and relationships, the arrangement/direction of a model, and the concern on how the variables (elements) are derived. Although the development process and the ultimate model form are more of a qualitative design, it embedded quantitative (statistical) data and approaches. More precisely, an embedded mixed-method design was used. The quantitative data or analysis involving residents' view is treated as a supporting or secondary/supplemental role in triangulating the findings of 'larger' qualitative methodology (see Creswell and Plano Clark [22]). Based on the mixed-method sampling (e.g., stratified random sampling, snowball sampling, expert sampling) [15] from various stakeholders (i.e., residents, public users, private developers and public officials), prior knowledge and extensive literature review, including existing studies' findings, institutional-social-ecological theories [14,17], best practices of self-organising systems, and tacit knowledge were involved [18]. Empirical field studies were also engaged, covering pilot studies, structured observation, government document archival search, in-depth (semi) structured interview, focus group discussion, self-reported questionnaire survey, and several analyses (i.e., descriptive analysis, Pearson Chi-Square, Monte Carlo analysis and 2-tailed Spearman analysis, and qualitative content analysis) (see Ling et al., 2016; Ling [15] for analysis and findings). The following are the data collected and analysed encompassing POS quality, local users' opinions and satisfaction on POS, property-rights variables, associations between property rights and POS quality, perception, and experiential data of property-rights failures implications on POS governance dilemmas and negative externalities, and the need and validity of a common-property approach with an exclusionary mechanism to local POS governance that includes its collective-action procedural institution (see Ling et al. [18]). 


\subsection{Choice of Performance Criteria and Techniques}

Performance criteria for institutional-social-environmental models must reflect the overall aim and specific objectives of the modelling activity set in the first step. This stage is highly related to the issues of validity and reliability. To determine the overall performance of model (objectives achievement), the estimation of the above parameters or variables and their associations and causal-effects link, whether they are accurately correct, unbiased, consistent, relevant, and statistically efficient, should be addressed. Both quantitative and qualitative techniques were engaged in determining the quality of the parameters within this institutional-social-ecological system. For instance, along with the theories of institutional effects on transaction costs and social dilemmas (social-ecological) interaction (as a standard), the quantitative method via statistical justifications with some cut-off points was used. These cover the exploratory factor analysis (EFA) for the construct validity, convergent validity, discriminant validity with factor loadings $\geq 0.3$ [23], Cohen's inter-rater reliability ( $\geq 0.7)$, inter-rater Cronbach's Alpha and Kruder Richardson-K20 reliability tests $\geq 0.5$, qualitative method (e.g., trustworthiness, credibility, and rigour), statistical significance of associations (i.e., $p \leq 0.05$ ), and causal-effect link between parameters (see the results and findings in Ling et al. [14] and; Ling [15]). For instance, for the structured observation on POS quality [15]. the reliability for the first stage of 172 POS samples, and second stage of 150 POS samples, with scores of $93.6 \%$ and 0.87 , and $92.7 \%$ and 0.85 were also obtained [14]. These reliability figures were acceptable, since both satisfied the benchmark of minimum $70 \%$, as well as 0.6 for inter-rater agreement and reliability [24]. The principal component analysis extraction and orthogonal rotation-based EFA were carried out to test the validity and categorisation of the 27 items of the questionnaire survey. The results of the Kaiser-Meyer-Olkin and Bartlett test were 0.822 and $\chi^{2}(200)=1721$, fulfilling the minimum rule-of-thumb of the sampling [25]. The two dimensions/components, i.e., (i) POS quality, governance and management issues of the local government; and (ii) POS users' behavioural consumption issues, comprising 27 items also achieve the minimal criterion of factor loading $(\geq 0.3)$. Moreover, Cronbach's alpha analysis and KR-20 analysis were performed to test the internal consistency. The results proved that the questionnaire items were reliable. That is, the Likert scale of 18 items have the $\alpha=0.858$ on the government's POS management and governance dimension; the 21 binary scale items related to the government's governance and management dimension were with the $\alpha=0.730$; and the nine Likert scale items of POS users' consumption behaviour dimension were with the $\alpha=0.501$, respectively. To ensure validity, reliability and credibility of the model development, technological tools were used to facilitate the above data recording and data analysis processes, e.g., an audio recorder was used to record the interviewees' responses, and via the computer software (i.e., Atlas Ti and Statistical Package for the Social Sciences), they were used to manage, organise and analyse the data. Crafting operational frameworks and a codebook reference, conducting a pilot study, and having consistent monitoring of the process were carried out. Triangulation techniques (cross-checking) were also employed to justify the estimation criteria of parameters [26].

\subsection{Identify Model Structure and Parameters}

It is an iterative process to re-confirm or reset the above-proposed parameters and structures of a model. This process consists of deciding whether particular parameters can be dropped or have to be added (i.e., is there any revision needed for the proposed parameters and structure?). Hence, the suggested parameters (see third step above) did not change much. There is, however, a slight alteration of property-rights issues: An addition of emergence of de facto perceived property-rights on title deed perception in, and removal of ill-defined rights issues from, local POS governance. The process (flow) and structure wise of the model remain the same as discussed in the stages of conceptualisation process and model structure/features determination above. As posited by Arhonditsis and Brett [27] cited in Robson et al. [5], an increase of complexity of model may not necessarily improve the model performance; thus, a balance between complexity and simplicity should be sought [28]. As for the flexibility issues, since the theories and scope are general and inclusive, it is 
believably flexible, because the parameters can generally encompass. Furthermore, they can predict other possible property-rights inefficiencies and common dilemmas, as well as different possible approaches and means permitted in general Ostrom's and Nelson's models (See Ling et al. [18]). That is a general and broad theory-based model may be able to predict responses to changes that bring the system outside its normal range under current conditions [5]. For the sensitivity of the model, as shown in the previous stage on the level of significance difference (i.e., $p \leq 0.05$ ), the outputs of the model regarding the quality of POS were quantitatively analysed [14]. The outcome (commons dilemmas of POS) showed that the output is indeed sensitive to the changes of the independent parameters (i.e., local diverse property-rights issues). This result can be partially found in Ling's et al. [14] work, reporting the p-value and lambda figure, in Table 2 below, as well as the results of Monte-Carlo Pearson's Chi-Square and Spearman analyses, particularly with respect to the strength (r) values, they can be obtained from Ling [15] (pp. 198-199, 324-325). For instance, the POS site handing over period (year) is associated with the POS quality with $32.5 \%$ ability to predict the quality of POS. That means the later the date of POS site handing over to local government, the higher the likelihood of good POS quality and vice versa. Simply, the earlier the POS is handed over or held longer by the government, the lower likelihood of good POS quality [14].

\subsection{Conditional Verification Including Diagnostic Checking}

The primary purpose of this re-assessment stage is to re-check or re-calibrate the above-made choice. This step is to ascertain whether the identified model, covering the output, the interaction of parameters, and process, is conditionally defensible, consistent, logical, and credible. In short, the verification stage is to produce the model right (as right as possible) [29]. This institutional model has also been verified by many means, especially in the stages of 2.5-2.7 above. Due to the limitation of resources (e.g., time and data availability) and case-specificity issue such re-checking, however, mainly involved the prior knowledge and theoretical triangulation [3]. Since this model is based on the case-study strategy, which addresses specifically the study area' issues, and the verification has been done beforehand in the 5-7th stages, such re-verification may be deemed unnecessarily repetitive. It is advocated to undergo validation (evaluation) instead. The re-checking is particularly crucial for the revision of two parameters (inefficiencies of property rights) above. By retaining the incompleteness of rights issues and re-looking into the similarities and differences between completeness and definition of property rights, the addition of de facto (perceived) rights in, and elimination of ill-defined property-rights issues from, the local POS governance system are necessary [15] (p. 316) (see Figure 4 below). This stage is indeed essential because, as argued by Jakeman et al. [3], it could build up the modeller's confidence in the model process, components, as well as outputs. More importantly, it could enhance the clients or model users, e.g., Sabah's land officers' and local authorities' confidence, which may subsequently assist in facilitating the validation process later. 
Table 2. Two stages of associations between the local four property-rights structure attributes and quality of POS.

\begin{tabular}{|c|c|c|c|c|c|c|c|c|c|c|c|c|c|c|c|}
\hline \multirow{3}{*}{\multicolumn{3}{|c|}{ Property-Rights Structure Attributes }} & \multirow{2}{*}{\multicolumn{3}{|c|}{$\begin{array}{c}\text { First Stage } \\
\text { POS Title Deed Existence }^{a}\end{array}$}} & \multicolumn{10}{|c|}{ Second Stage } \\
\hline & & & & & & \multicolumn{3}{|c|}{ POS Community Existence ${ }^{b}$} & \multicolumn{3}{|c|}{ POS Title Deed Transfer to Local Government ${ }^{c}$} & \multicolumn{4}{|c|}{ POS Site Handing over Period to Local Government (year) ${ }^{\mathrm{d}}$} \\
\hline & & & $\begin{array}{l}\text { Without } \\
\text { Title }\end{array}$ & $\begin{array}{l}\text { With } \\
\text { Title }\end{array}$ & Total & $\begin{array}{c}\text { Without } \\
\text { Community } \\
\text { Management }\end{array}$ & $\begin{array}{c}\text { With } \\
\text { Community } \\
\text { Management }\end{array}$ & Total & $\begin{array}{l}\text { POS Title } \\
\text { Deed has been } \\
\text { Transferred }\end{array}$ & $\begin{array}{l}\text { POS Title Deed } \\
\text { has not been } \\
\text { Transferred }\end{array}$ & Total & $\begin{array}{c}\text { Site Handed } \\
\text { over before } \\
\text { the Year } 2000\end{array}$ & $\begin{array}{l}\text { Site Handed } \\
\text { over between } \\
2000 \text { and } 2009\end{array}$ & $\begin{array}{l}\text { Site Handed } \\
\text { over in the Year } \\
2010 \text { and above }\end{array}$ & Total \\
\hline \multirow{6}{*}{ Quality of POS } & \multirow{3}{*}{ Poor } & Count & 22.0 & 68.0 & 90.0 & 62.0 & 6.0 & 68.0 & 56.0 & 12.0 & 68.0 & 56.0 & 12.0 & 0.0 & 68.0 \\
\hline & & Expected count & 11.5 & 78.5 & 90.0 & 55.3 & 12.7 & 68.0 & 56.7 & 11.3 & 68.0 & 40.8 & 19.0 & 8.2 & 68.0 \\
\hline & & Column percentage $\%$ & 100.0 & 45.3 & 52.3 & 50.8 & 21.4 & 45.3 & 44.8 & 48.0 & 45.3 & 62.2 & 28.6 & 0.0 & 45.3 \\
\hline & \multirow{3}{*}{ Good } & Count & 0.0 & 82.0 & 82.0 & 60.0 & 22.0 & 82.0 & 69.0 & 13.0 & 82.0 & 34.0 & 30.0 & 18.0 & 82.0 \\
\hline & & Expected count & 10.5 & 71.5 & 82.0 & 66.7 & 15.3 & 82.0 & 68.3 & 13.7 & 82.0 & 49.2 & 23.0 & 9.8 & 82.0 \\
\hline & & Column percentage $\%$ & 0.0 & 54.7 & 47.7 & 49.2 & 78.6 & 54.7 & 55.2 & 52.0 & 54.7 & 37.8 & 71.4 & 100.0 & 54.7 \\
\hline \multirow{3}{*}{\multicolumn{2}{|c|}{ Total }} & Count & 22.0 & 150.0 & 172.0 & 122.0 & 28.0 & 150.0 & 125.0 & 25.0 & 150.0 & 90.0 & 42.0 & 18.0 & 150.0 \\
\hline & & Expected count & 22.0 & 150.0 & 172.0 & 122.0 & 28.0 & 150.0 & 125.0 & 25.0 & 150.0 & 90.0 & 42.0 & 18.0 & 150.0 \\
\hline & & Column percentage \% & 100.0 & 100.0 & 100.0 & 100.0 & 100.0 & 100.0 & 100.0 & 100.0 & 100.0 & 100.0 & 100.0 & 100.0 & 100.0 \\
\hline
\end{tabular}

Source: Ling et al.; and Ling [14,15]; Inferential statistics at significant value 0.05: a $\chi^{2}(1, N=172)=22.984, p=0.000 ; \lambda=0.17$, Proportional Reduction Of Error $=17.0 \%$ (Significant);

${ }^{\mathrm{b}} \chi^{2}(1, N=150)=7.938, p=0.005 ; \lambda=0.03$, Proportional Reduction Of Error $=3.0 \%$ (Significant) ${ }^{\mathrm{c}} \chi^{2}(1, N=150)=0.086, p=0.769 ; \lambda=0.00$, Proportional Reduction Of Error $=0.0 \%$

(Non-significant); ${ }^{\mathrm{d}} \chi^{2}(2, N=150)=30.047, p=0.000 ; \lambda=0.325$, Proportional Reduction of Error $=32.5 \%$ (Significant). 


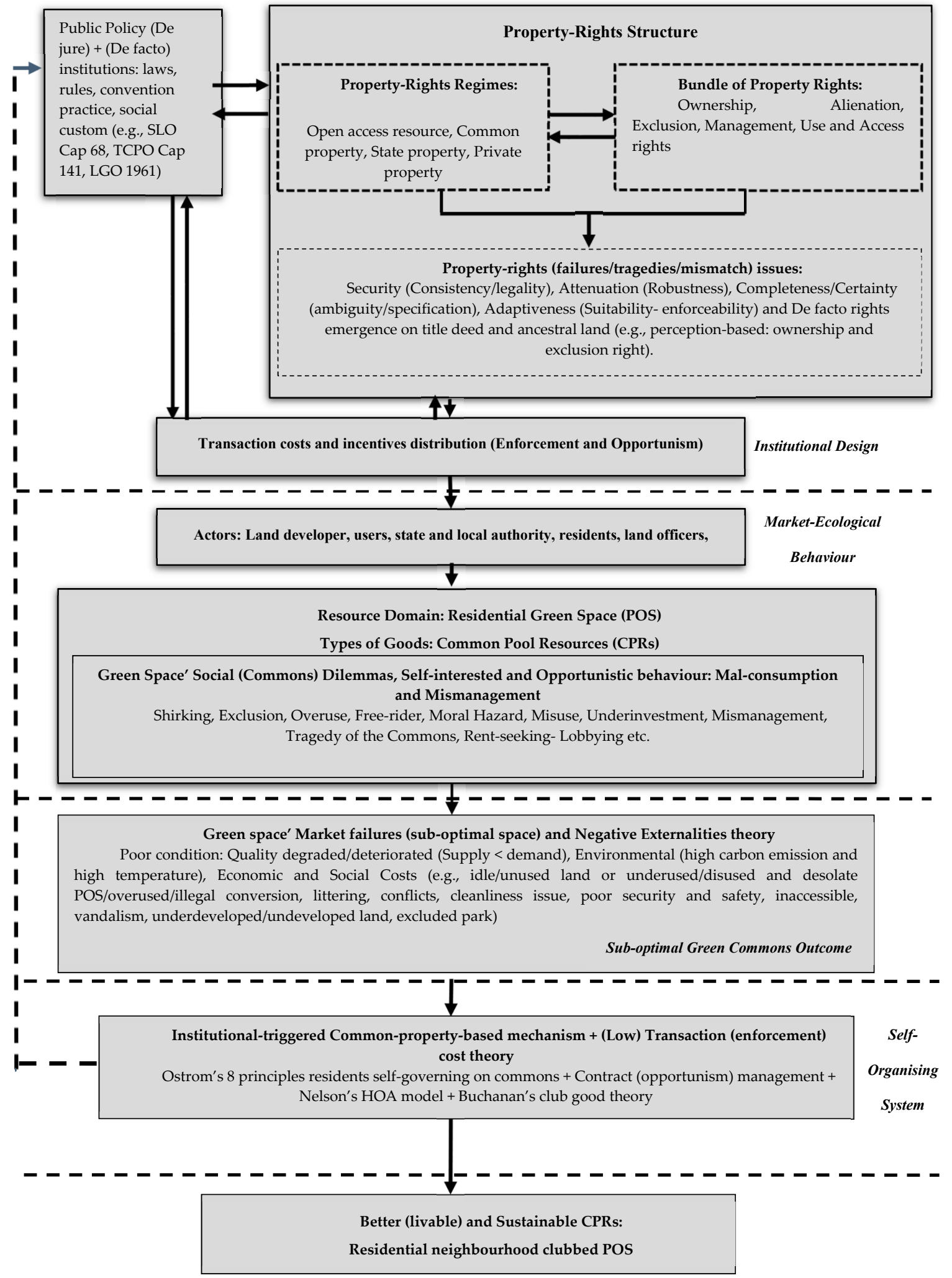

Figure 4. Verified problem-solution-based institutional-social-ecological interaction model.

\subsection{Quantification of Uncertainties}

Uncertainty may cause errors and misleading information. It is important, but is usually difficult, to deal with the study's institutional-social-ecological model. Uncertainty in the models (see Walker et al. [30]) stems from incomplete system understanding in terms of which processes and 
parameters to include and how they interact. Sources of uncertainty in this model are various, but only the prominent ones were included as follows: (i) Uncertainties in terms of associations between local property-rights and POS quality ([14]; see Table 2 above). There may be an issue whether the associations between property right and POS quality are accurate, because the dependent variable: POS quality was in a categorical and ordinal data form that is subject a lower power of non-parametric analyses (i.e., Chi-Square test). Next, there are (ii) uncertainties in the parameter/variables values that especially deal with property-rights issues, POS governance dilemmas and proposed Ostrom's eight design principles in the local context. Parameter ranges, taken from the scientific literature and tacit (prior) knowledge, are not always relevant to the conditions at a particular site, and the above subjective calibration (verifications) "by eye" or even with a mixture of quantitative (statistical) approach may not be defined mathematically optimal. The justification of the local model parameters via statistical method may be erroneous, due to the rather lenient rules of thumbs set for the exploratory factor analysis and Cronbach's Alpha analysis. Albeit the items (parameters) of survey questionnaires have satisfied the minimum criteria, i.e., factor loading is $\geq 0.3$, and Cronbach's Alpha is $\geq 0.5$, some scholars arguably contested these requirements. Although all items have Cronbach's Alpha of 0.5 that signifies an internal consistency, it also means $0.5(50 \%)$ room for errors. Another issue is the exploratory reason; the figure 0.3 of the factor loading coefficient is rather low as some of them argued it should be at least 0.5 and above to show the parameter validity.

\subsection{Model Evaluation or Testing (Validation)}

The model must be evaluated in the light of its objectives. The success of a model must ultimately be assessed in terms of how well it fulfils the purpose specified in step 1 and its credibility (procedure wise). There are two forms of validations, namely quantitative, e.g., statistical approach and qualitative evaluations [6]; however, the focus is on the latter, due to unavailability for quantitative testing. The core component of qualitative testing is a face validation (experts' validation) (see Bockstaller and Girardin [31]).

Despite some downsides of this subjective method (e.g., prone to bias), it still has few strengths like convenience, perhaps time and cost saving. Within such expert judgement, which ranges, e.g., from 2 to 50 persons [32], it can adopt either the member checking that involves the participants during previous data collections or the peer debriefing that requires an external reviewer as the third party. However, the member-checking approach was selected (See Creswell [33]; and Creswell and Miller [34] for more procedural applications and advantages of member checking over the peer debriefing). The participants (members) re-involved not just to confirm the findings, but also act as experts in validating especially the formulated conceptual solution part (see Lincoln and Guba [35] (p. 314) describe member checks as "the most crucial technique for establishing credibility" in a study). Along with that, the "theoretical sampling and saturation", "thick and rich description", "triangulation" were adopted to enhance the researcher's ability to provide the rigour of the findings [33]. Besides, another issue contributes to this expert validation approach is standard questions. The standard questions concern the construction, operation and output of the model [6].

\section{Expert Opinion System in Model Validation}

Since the expert opinion (member checking) was employed, members or experts were sampled via non-probability techniques, i.e., purposive sampling (expert sampling) and convenience sampling. The convenience sampling has been chosen, because the experts' availability was considered. Furthermore, those selected members are indeed experts who have much experience and knowledge. They are well-versed about both the real system and the product or model as a whole: The process and relationship (causal-effects) between the components (factors, issues, conceptual solution and consequences of POS). More precisely, this time expert sampling solely considered the government officers because, compared to residents (POS users) and private developers, the former has more experience and knowledge about the practice (institutions), especially relating to NT POS. Furthermore, 
they, as intermediate persons, involved in the entire process, including subdivision process, POS title issuance, site handing over, transfer of POS, monitoring to management, maintenance and consumption of spaces. The size of the sample was only five public officials, including three from the land office (Lands and Surveys Department) and two from the local authorities (Kota Kinabalu City Hall and Penampang District Council) of Sabah, Malaysia, respectively. Their opinionated and experiential data about the model validity were obtained via the in-depth face-to-face semi-structured interviews, where an audio recorder has taped their responses, and some were field noted, and subsequently transcribed. There are three primary reasons for such sample size: (i) Five is within the range or allowance of minimum 2-50 persons according to literature; (ii) this number was enough to achieve saturation; and (iii) since this is a sort of re-validation (reconfirmation) on the validated findings of the previous studies $[14,15]$, the five samples may suffice. Prior to the formal individual interview session execution, the model (product), its development process and findings, including the verified conceptual model (see Figure 4 above), and a list of questions were attached and sent to the five experts via email. In light of the validation's credibility, the following questions were posed:

1. How accurate or realistic and optimal are selected parameter/components (factors) (current practice-based property-rights structure, POS issues, property-rights issues, proposed solution (idea and mechanism) and POS outcome?

2. Is the model correct and precise in terms of its components' process flow and relationship, and structure presentation?

3. Is the model flexible enough, i.e., how well can the model function under unusual conditions, e.g., can the model flexibly sufficient to perform as it is intended to when it faces unprecedented instances?

4. Generally, is the model behaving as expected? Or does the model meet its purpose/intention above that specified beforehand, i.e., (a) does the first basic model provide a general and better understanding in the process of the institutional system and POS issues emergence? (b) does the formulated solution suffice to improve the issues and in turn rendering better POS quality? And does the model suffice to predict the outcome of POS quality via the opportunistic behavioural dilemmas of stakeholders in POS governance (management and consumption) that triggered by the current institutional property-rights issues?

5. Above all, remaining in this institutional behavioural context in POS, in what ways can the understanding of the model be improved, as well as how model's function and credibility (or is there any amendments-addition or reduction of items and components, due to over simplicity and complexity issues) should be performed?

Next, for the analysis of data in the validation stage, content (thematic) analysis was the principal analytic technique involved in analysing the transcribed five experts' responses. It extracted the main ideas and codes from the five experts' data, e.g., on the relationship of institutions with POS quality, property-rights issues, POS issues, and solution parameters to the POS issues. The analysis was facilitated by using Atlas. Ti. Figure 5 below is the overall outcome of the interviews of the five experts, which the result is presented in the mind-mapping form. 


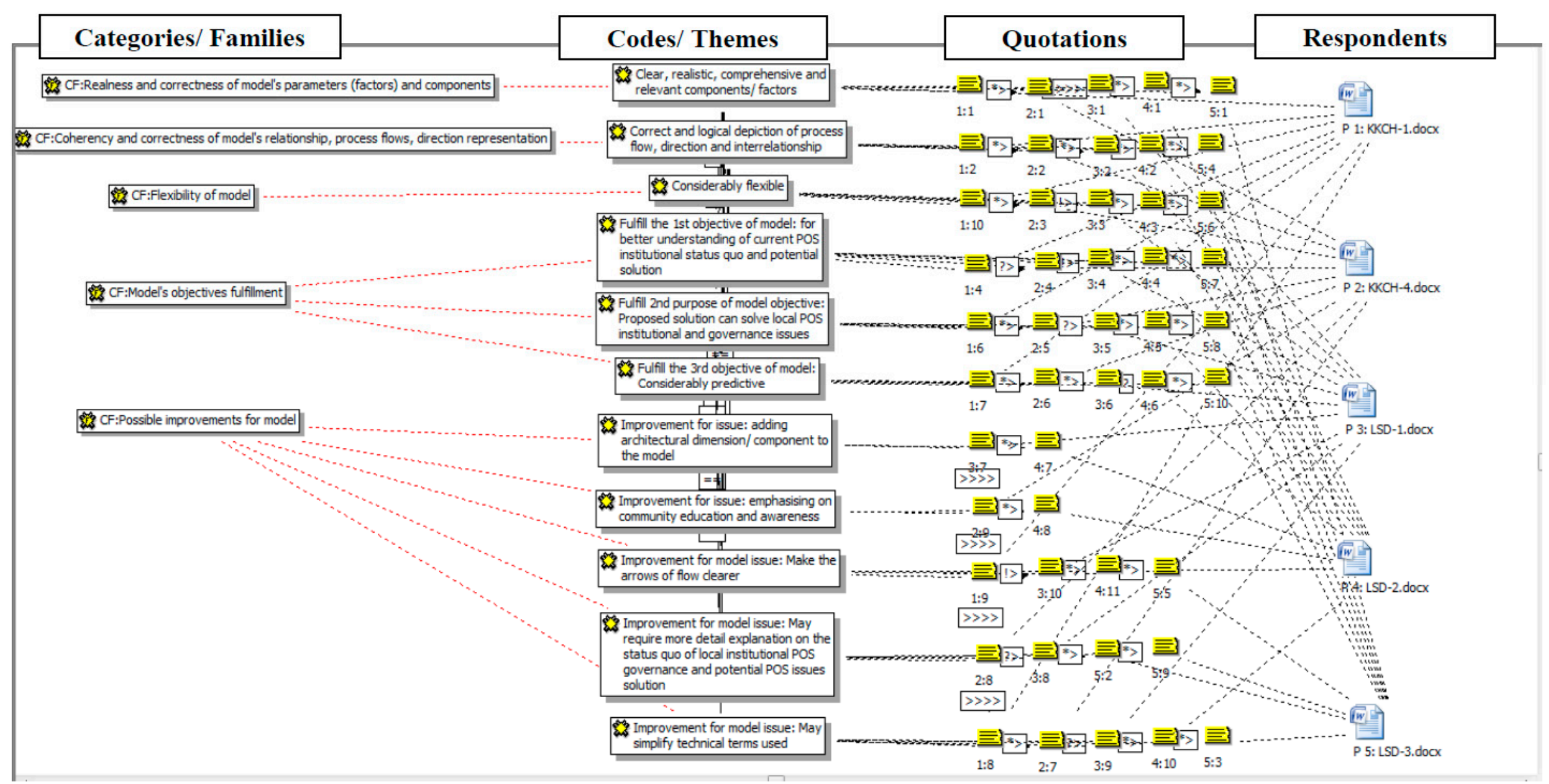

Figure 5. The result of the model qualitative validation of the five experts-interrelationships between categories, codes and quotation. 
The above result shows a more general and fuller picture of what are the components, process and relationships involved, including five categories (families), 11 codes (themes), and over 45 quotations (interview responses), and types of connections between the codes and quotations. Five different policy-makers contributed different ideas and opinions about the model, which their responses are reportedly justifying, supporting/confirming, continuing, explaining and expanding each other's view with respective symbols of representation. The codes generated are interrelated with each other. For instance, the above codes of "clear, realistic, comprehensive ... components" and "correct and logical depiction ... " are considered "a part of" the codes of the fulfilment of all the three objectives of the model. That is, the model is vital for a better understanding of the current local institution and POS governance status quo, for solving the arisen POS commons dilemmas issues, and lastly for predictive purposes.

Since there were five improvements, each improvement is continued with another new or different improvement. Moreover, although the model's components and process flows are real, logical, and correct, which fulfilled the objectives (a part of), the codes "associated" with the improvement of the model, i.e., simplification of terminologies and clarification of structural flows, are required. Lastly, each code is categorised under each general category or family, namely within the category of the "fulfilment of the model's objectives", it has three codes, as illustrated. They are useful acting as the framework for the following specific five questions. That is, only some results (quotations and codings) in textual form were selected and presented below.

I. How accurate or realistic and optimal are selected parameter/components (factors) (i.e., current practice-based property-rights structure, POS issues, property-rights issues, proposed solution (idea and mechanism) and POS outcome?

It is discovered that all of the experts opined that the components selected for this institutional-social-ecological model are realistic and optimal as they were indeed based on the local empirical evidence; hence, they sufficiently represent the current interrelationship between/effects of the institutional system of the POS governance, consumption and management issues, and Ostrom's collective action as solution. Refer to the Supplementary Material for the empirical instances of two supporting responses provided by two different interviewees (i.e., LSD-1 supports/confirms the LSD-2).

II. Is the model correct and precise in terms of its components' process flow and relationship and structure presentation?

Overall, it is found that all the respondents had simultaneously agreed that the model's structure, inter-relationships, and process flows (steps and directions) presentation are logical and correct. As agreed, the model's arrows and linkages can be related to other components, starting from the initial point (i.e., local institutional structure status quo) to the mid-point (i.e., institutional and transaction-cost triggered social-POS interaction issues) and to the final point (i.e., institutional-redesigned solution via Ostrom's collective action). Furthermore, the depiction of the model's process flow is unfolded and streamed smoothly. Hence, the Supplementary Material shows the instances of two supporting responses between one local authority and one land officer (KKCH-1 supports LSD-1).

III. Is the model flexible enough, i.e., how well can the model function under unusual conditions, e.g., can the model flexibly sufficient to perform as it is intended to when it faces unprecedented instances?

It is discovered that all of the respondents viewed the model is seemingly and considerably flexible. However, it is not too flexible until it loses its very institutional and social-ecological interaction essence, but it is still flexible enough to "accommodate" other possible events (e.g., on other resources like open spaces in other land uses), or the unprecedented situations still can fall within the scope and be explained by the above structure (similar steps and flows). Such flexibility of the model is possible, because all the defined components, such as institutional (property-rights and transaction-costs/incentives)-triggered social-ecological interaction issues and Ostrom's solution are 
theory-based, which is general and widely-inclusive. Thus, two responses between one local authority and one land officer (i.e., KKCH-4 justifies LSD-2) were shown (see the Supplementary Material).

IV. Is the model behaving as expected? Does the model meet its purpose (has the model answered the research questions)?

All of the respondents had altogether concerted that the model can reflect and represent the real local phenomenon. That is, the model can deliver its capability and functions ranging from (i) providing in-depth understanding of existing local institutional and POS system and the need of emergence of Ostrom collective mechanism as solution; (ii) reasonably addressing the aforesaid institutional and POS governance, management and utilisation issues via Ostrom's eight principles and Nelson's procedural community association formation; to (iii) predicting the POS quality/wellbeing via the social-ecological behavioural interaction, but with some reservations and notes. This is possible, especially when the above questions on the model's structure, relationships, process and components are realistic, correct, logical and comprehensive. The result shows all the three codes (based on the three objectives) and their respective quotations simultaneously. Thus, refer to the Supplementary Material for the supporting, expanding and justifying responses between one local authority and two land officers (i.e., LSD-1 justifies KKCH-4 and also supports LSD-2).

V. Remain in this institutional behavioural context in POS; in what ways can we improve the understanding of the model, as well as model's function and credibility (should there be any amendments-addition or reduction of components, due to over-simplicity and over-complexity issues performed?)

Although the overall model is considerably fit, there is a complexity issue. There are five model improvements recommended by different policy-makers, which are coded as follows; "improvement for issue: adding to architectural ... ", "improvement for issue: emphasising community education ... ", "improvement for issue: makes the arrows of flow clearer", "improvement for issue: may require more detail explanation ..." ", and lastly, "improvement for issue: may simplify technical terms used". Emphasising the community education and adding architectural dimension to the model were only coined by two respondents, while the remaining three improvements were focused on by the majority of the respondents $(80 \%)$.

Some instances of explaining, supporting, expanding and justifying responses among the five interviewees (e.g., KKCH-4 explains LSD-1 and the latter then supports LSD-3) on the mainly aforesaid three main improvements, were in the Supplementary Material. There are two reasons for such selective improvements adoption: (i) The minor improvements suggested in the addition of community awareness and education and architectural factors in this current core institutional-social-ecological context are deemed unsuitable and irrelevant, because they are viewed as supplementary alternative, rather than as a necessary concern; and (ii) the most suggested above (iii) improvements indeed make much sense, which not only make the model becomes more explicit, they also foster its credibility. Thus, those modifications were made to improve the old verified model depiction, of which the new model presentation is shown (Figure 6) below.

Based on the newly revised model, i.e., the three-suggested-improvements-based social-ecological model, including the numbered arrows, texts addition and rewordings, and slight restructure of the model (see Figure 6), it now has a more precise and simpler terms and structure/flow presentation and a better depiction on the proposed solution. As such, this model plausibly seems more useful, unambiguous, and self-explanatory for the decision-makers. Therefore, this 10-step-based institutional-social-environmental model suffices to be applied in a real-world POS planning and governance policy context, especially when it is believed it may bring high confidence to them in managing and facilitating their decision-making. 


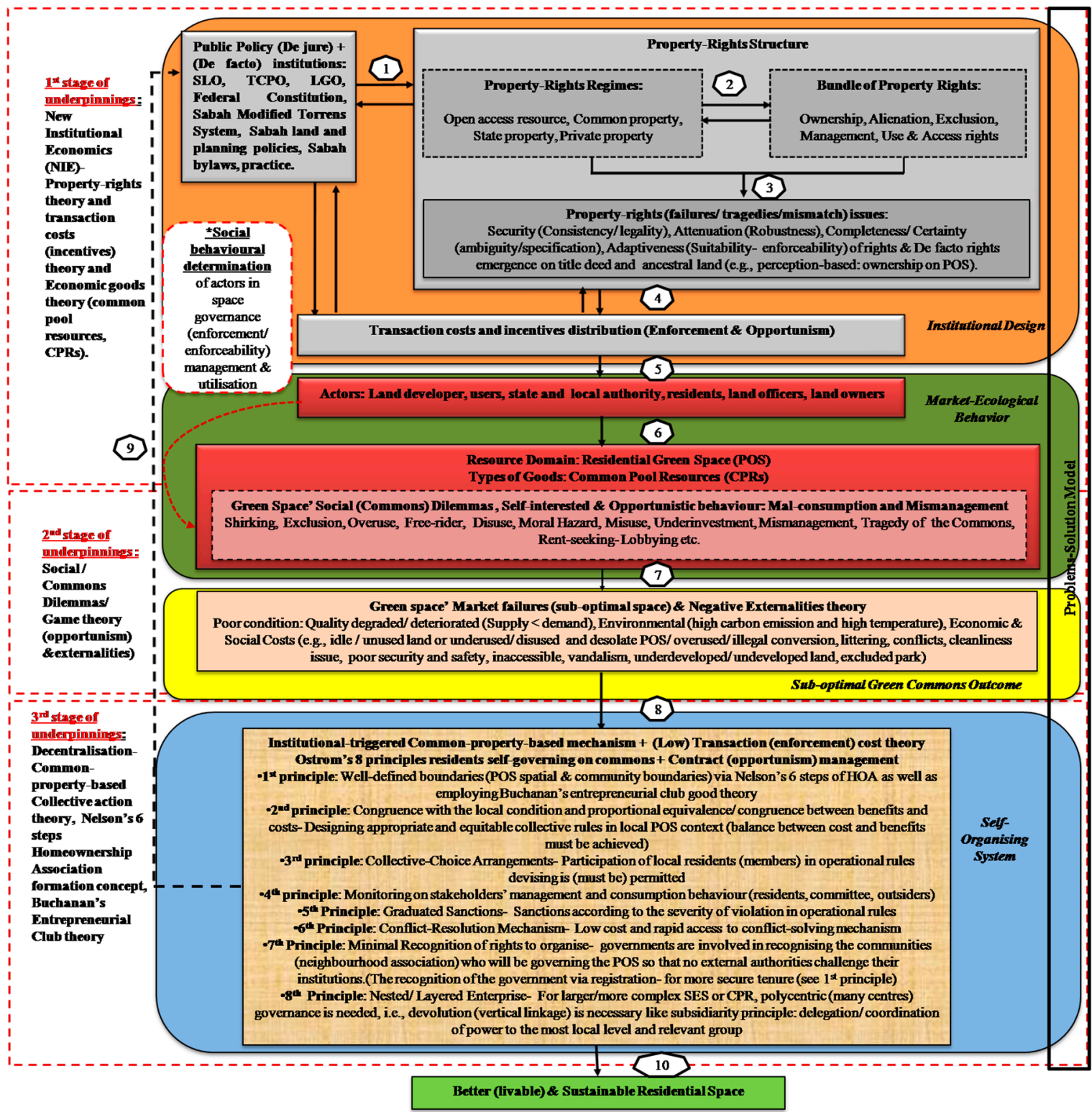

Figure 6. Validated (extended) conceptual social-ecological system model.

However, for the interest of fulfilling the model's criteria and principles of being concise yet straightforward, a less complicated and all-inclusive model is necessary [36,37]. That is, the triangle model by Munasinghe [21]) is showcased below. Furthermore, by presenting the categorisation of similar components into few concepts, the previous extended version of the model structure of Figure 6, generalised into this triangle-shaped model, is shown in Figure 7 below.

Below are the descriptions of the triangle model regarding the structure (components) and the links and processes involved. The relevant elements of the micro/focal structure are: (a) The institutional environment; (b) the institutional arrangement- POS governance system; (c) the market-POS behaviour; and (d) the POS quality and sustainability outcome. Besides, there are several elements, act as external or macro factors, such as (e) the related and broader political, economic, social settings and a related ecosystem. These macro settings, which encapsulate the focal context of the triangle circles (interior elements) with the dashed line may determine the latter changes and vice versa. 


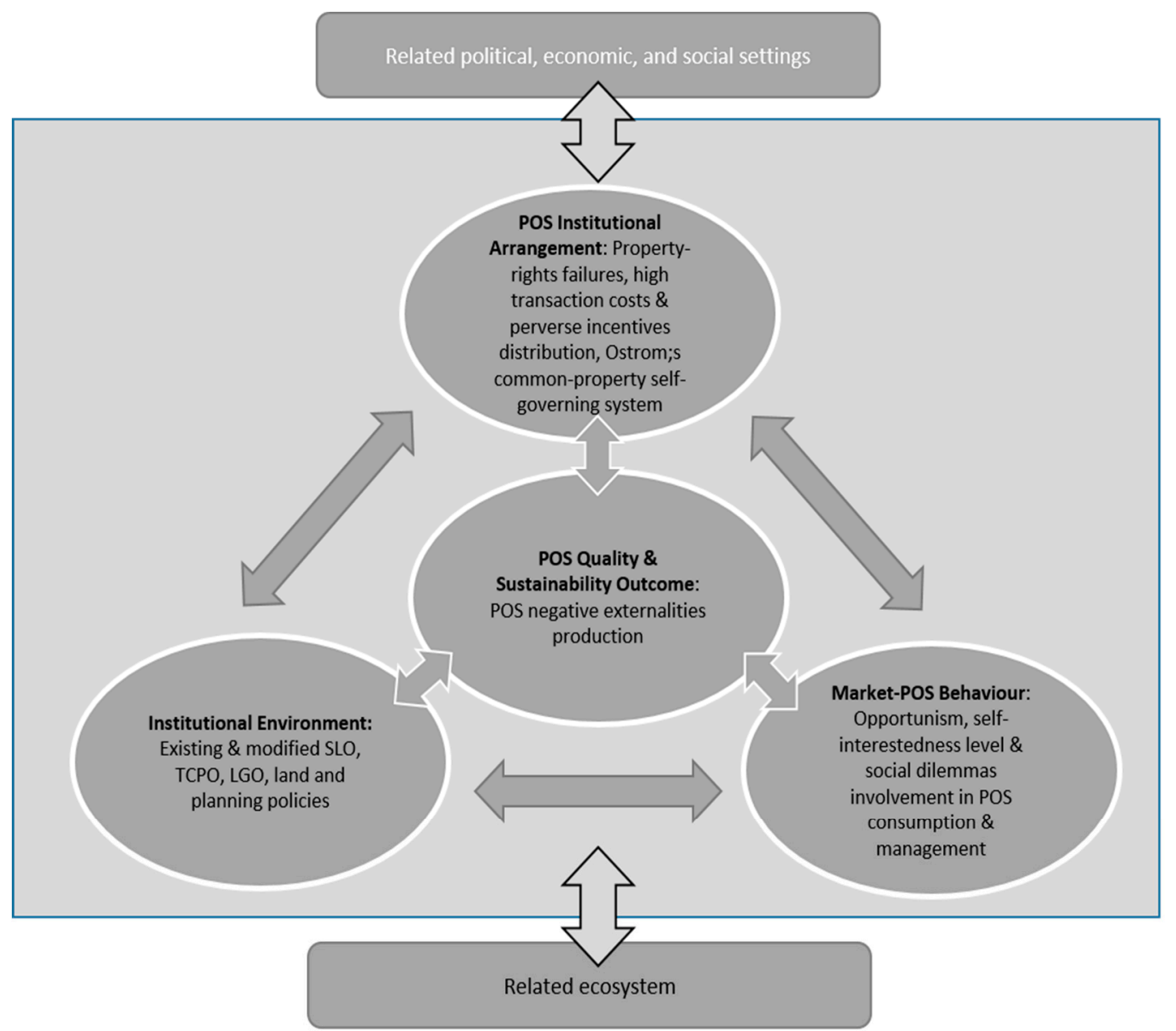

LEGEND

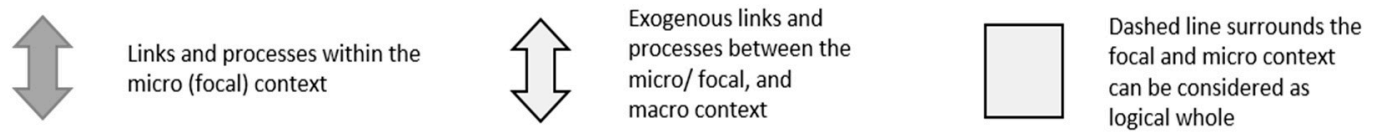

Figure 7. The validated triangle model of the institutional-social-ecological system showing interrelationships among institutional environment, POS governance system, market behaviour, and POS quality and sustainability outcomes.

Therefore, to bridge and reconcile the terminologies used in the two different validated models forms, namely Figures 6 and 7, the similarities they have in common were described. That is the questions of how are those terms used in the generalised structure explaining and accounting for the main variable (parameter), and ideas and theories formed in the extended version were addressed. Finally, for the practicality and usefulness of the model in the local setting, its operationalisability and operationalisation process are also explained below.

I. Institutional environment:

As a part of the institutional design, within this component that acts as a prime mover, there are numerous elements similar to the extended model (Figure 6). The institutional system includes the existing supreme law- Federal Constitution and Sabah's local institutions: The Town and Country Planning Ordinance (TCPO), the Local Government Ordinance (LGO), and the Sabah Land Ordinance (SLO), bylaws, regulations, the Modified Torrens System, public policies and practice. The local matters include the issues of POS title deed issuance, publicness of POS, the existence of community assistance, transfer of title, POS site handing over, etc. As Musole [38] stated, such 'institutional environment', as a macro-analytic perspective, encapsulates property rights and institutional change. For instance, 
changes in the existing law or new adaptive laws/policies adoption should be made in order to steer the property regime towards self-governing collective action.

II. Institutional arrangement-POS governance system:

Similar to the institutional environment, such governance or order system in POS is part of institutional design or framework. More precisely, as Musole [38] posited, it is considered as an institutional arrangement or system (micro-analytic perspective). The institutional arrangement matters cover and revolve around the property rights structure (e.g., the allocation of ownership and management regime, such as common-property-regime via the homeownership association and contractual system), as well as its rights issues (e.g., attenuation and incompleteness of rights). Besides, transaction costs and (perverse) incentives distribution in implementing such public domain governance, e.g., high transaction costs in enforcing management, maintaining and monitoring duties of POS are part of the micro institution system. One can notice that the proposed institutional property regime re-alignment to the self-governing system, which resembles the second last part of the extended model, can be deemed the governance system of POS as it can curb the abovementioned property rights issues and high perverse incentives and transaction cost.

\section{Market-POS behaviour:}

Market-POS setting herein is taken as actors or stakeholders who involved in POS affairs (provision and demand). These include the issues of POS governance, typology of goods of POS (e.g., CPRs or club goods), POS management, maintenance, consumption, accessibility, etc. The actors cover land officers, state government and local governments, private suppliers (developers), public users, residents, and landowners. The interactional behaviour of social-POS categories can either be opportunistically/rationally or non-opportunistically. If it was under the behaviour group of selfish and opportunistic, these are the list of possible rational behaviours (or called commons dilemmas) that may be adopted by stakeholders to sort of protecting and maximising their interest, while compromising others, such as shirking, lobbying, overexploitation (see the tragedy of the commons), moral hazard, underinvestment, free-riding, rent-seeking, illegal exclusion, mismanagement.

IV. POS quality and sustainability outcome:

Similar to the extended model, under the caption "sub-optimal green commons outcome", this component emphasises the quality, condition, wellbeing, efficiency and sustainability of POS. This component looks into the perspectives of negative externalities and market failures of POS. For instance, the sub-optimality of POS include poor conditions and social costs as follows: Degraded quality of POS; idle POS or underused POS; disused and desolate POS; overused POS; illegal conversion of POS; POS cleanliness issue; inadequate security and safety within POS; inaccessible POS; vandalism issue in POS; excluded park; and so on. If those externalities and POS common dilemmas result, they likely entail poor POS quality and unsustainable POS. This phenomenon is precisely akin to the existing status quo of POS outcome [15]. However, this component also covers and represents the possibly better, liveable, and sustainable residential POS outcome, if the proposed self-governing collective action is applied, which requires the change of the above POS institutional design that consequently curtails stakeholders' opportunistic behaviour.

V. Related and broader political, economic, social setting and ecosystem:

These components most likely act as macro (broader) factors that play significant roles in determining the micro (focal) context of the above four institutional-social-ecological related components. For instance, these components encompass several subjects, such as economic development and crisis, socioeconomic background, demographic trends, political stability, other governance system, macro markets, technology, climate change and pollution. Apart from the components or structures involved, the links (influences) and processes included in this model are also relevant to be discussed. The influences are bidirectional for both the exogenous (macro) and focal 
(micro) contexts, whereby a nexus is formed. These interrelationships occur between the exogenous (macro) factors and focal (micro) institutional-social-ecological setting and within the micro or focal environment itself. Begin with the focal context (within the micro context), ultimately, the final output to be focused is the concern on the quality and sustainability of POS outcome, in which the three interlinked components influence it. Following the influences of processes sequentially, the prime mover institutional environment (e.g., Sabah constitutions, laws and regulation) is able to influence POS outcome by setting conditions and rules to the POS governance system (e.g., property-rights on the consumption, management and ownership, as well as failures/inefficiency of rights emergence). By virtue of the institutional change, it determines the behaviour of actors, who participate in POS resource system interaction. Based on incentives and costs analysis and distribution, they may choose whether to act opportunistically in POS management and use, which thus influence the quality or wellbeing and sustainability of POS.

Based on the step-by-step process, the overarching institutional environment has an impact on the outcome of POS quality and sustainability. If the current institutional environment that influences governance system has detrimentally affected and modified the POS system, resulting in poor quality of POS via the opportunistic action and behaviour of actors (e.g., misuse and mismanagement), such negative impacts on the POS quality may likely trigger an institutional change either by revising the laws (institutional environment) or reallocating the property-rights system and transaction and incentive distribution [39]. Furthermore, it can be signified that the exogenous influences from related ecological systems or social-economic-political settings can affect any component within the logical whole. That means if the present political system changes, it is possible that the entire institutional design (laws and property-rights system), which influences social behaviour, as well as quality and sustainability, may alter. That is if the political intention and economic will towards the environmental conservation concerns are weak and are downplayed, then the laws and governance system crafted may not necessarily favour towards the interest of POS quality and sustainability. However, since the influence can go vice-versa, i.e., due to the severely degraded quality of POS by the present institutional design, it is likely to trigger a movement politically from both international and national firms to improve the status quo. Therefore, this entire interdependent system of both exogenous and focal components is necessary for ensuring the well-being of POS.

To make the institutional-social based POS issues and management model more practical, the modellers, especially the land officers, planners and landscapers from the respective departments, including Lands and Surveys Department, Kota Kinabalu City Hall, and Penampang District Council, can operationalise it in the local residential POS. The model helps them understand and predict the process and flow of how and why such POS quality is resulted by the current local/similar institutional system. For instance, under existing or similar laws resulting in unclear rights, restricted (disbenefitting) private rights, and misallocated regime that contribute to high enforcement (management) cost and perverse incentives, modellers can identify and tell that stakeholders are and may likely to act selfishly by not managing POS or by misusing (vandalise) the space, which thereby leads to poor POS condition and quality. Such social costs, thus, call for a revise of political/institutional settings in order to render better POS governance and quality.

\section{Discussion of the Conceptual Institutional-Social-Ecological System Model}

The findings have supported the position of Bennett et al. [6] that a series of questions for model evaluation is vital as a means for identifying the possible improvements for a model, setting out a more precise picture, and contributing to better understanding of the model. Since this finding showed that it is necessary to improve the model by expanding the proposed solution via components addition, which in a way contributes to the complexity of the model, it is in disagreement with Arhonditsis and Brett's [27] position that increasing complexity does not improve its performance. Instead, it espouses Fulton's et al. [28] idea that increasing the complexity via further elaboration of the model to a particular desirable degree may be beneficial, especially for better understanding purposes. 
Since the result was solely generated from the qualitative testing (expert validation), the current local results and findings were valid and credible, which has asserted Jakeman's et al. [3] stands that the qualitative testing methodology for the validation stage is highly recommended. As for the findings of the model concerning its capability and role in improving the understanding of the system, this has been parallel with Robson's et al. [5] claim that models of most varieties allow improvements in understanding the system function by highlighting inter-relationships among variables. Finally, since the local institutional-ecological model was considered flexible, it supports the contention of Robson et al. [5] about the advantage of a theory-based model.

\section{Conclusions}

Except for the sixth and ninth steps, which are more of using quantitative techniques to determine the parameters performance, sensitivity, and uncertainty, the 10 steps of Jakeman's et al. [3] are generally applicable, flexible, and valid to the qualitative conceptual theory based institutional-social-ecological (problem-solution) modelling. The development and validation procedural framework has adequately proven to improve the qualitative modelling standards and its quality by enforcing an explicit consideration of the scientific and policy context of the model. To sum, the model may potentially improve POS governance and its quality in Sabah. First, the institutional-social-ecological model helps decision-makers understand better and explain why and how do the current local laws, policies and practice of POS governance (as a root cause) affect POS quality and sustainability; hence, institutional elements and any of its change shall be taken into account for POS protection policies. This also means that the model serves as a predictive tool, where it can provide precautionary measures to preclude and mitigate POS commons dilemmas and quality issues. For example, the model can inform stakeholders that the current local institutional-triggered social-POS behavioural system is indeed problematic and unsustainable, particularly under the maladaptive local-authority-governing POS regime; hence, an adaptive re-engineering of these POS institutions is necessarily imperative. Furthermore, albeit this study is confined to the study area (Sabah), the model has employed the theory-based design, the problem-solution based design, as well as the conceptual model describing causal-effect links. This entails that those model designs are sufficiently flexible and inclusive for other jurisdictions or States and other countries to adopt, particularly when they face the similar issues of POS commons dilemmas under a complex property-right system or similar issues in other commons settings and ultimately require similar institutional social-ecological countermeasures and framework for informed decision-making. Last but not least, this paper suggests and offers multidisciplinary lens and insights to both scholars and policymakers. The POS management and quality model using the social-ecological system-based new institutional economic approach that consists of property-rights, commons, transaction costs, opportunism and collective action analytic framework in dealing with human-environment interaction behaviour is innovative and pivotal in addressing the local POS dilemmas. However, the model requires more attention and field study (validation), considering other stakeholders' views, e.g., via a series of focus group discussion. This is important to ensure a holistic, practical model that ultimately contributes the decision-makers to designing and planning a vibrant and sustainable environment within a neighbourhood community.

Supplementary Materials: The following are available online at http:/ / www.mdpi.com/2079-9276/7/4/62/s1, Content analysis and textual results of five public officials.

Author Contributions: Conceptualization, G.H.T.L. and P.C.L.; Methodology, G.H.T.L. and P.C.L.; Validation, G.H.T.L. and P.C.L; Formal Analysis, G.H.T.L.; Data Curation, P.C.L.; Writing-Original Draft Preparation, G.H.T.L. and P.C.L.; Writing-Review \& Editing, G.H.T.L. and P.C.L.; Visualisation, P.C.L.; Supervision, G.H.T.L.

Funding: This research was funded by the Ministry of Education Malaysia and Universiti Teknologi Malaysia through the Research University Grant (GUP) with grant number of Q. J130000.2621.15J19.

Acknowledgments: The authors would like to thank the anonymous reviewers for their valuable comments and suggestions to improve the quality of the paper. 
Conflicts of Interest: The authors declare no conflict of interest. The funders had no role in the design of the study; in the collection, analyses, or interpretation of data; in the writing of the manuscript, and in the decision to publish the results.

\section{References}

1. Beakley, G.C.; Chilton, E.G. Design Serving the Needs of Man; Macmillan Publishing Co. Inc.: New York, NY, USA, 1974.

2. Little, R.J.A. Pattern-mixture models for multivariate incomplete data. J. Am. Stat. Assoc. 1993, 88, 125-134.

3. Jakeman, A.J.; Letcher, R.A.; Norton, J.P. Ten iterative steps in development and evaluation of environmental models. Environ. Model. Softw. 2006, 21, 602-614. [CrossRef]

4. Forbus, K.D. Chapter 9. Qualitative Modeling. In Handbook of Knowledge Representation. Foundations of Artificial Intelligence; van Harmelen, V.L.F., Bruce, P., Eds.; Elsevier: Amsterdam, The Netherlands, 2008; pp. 361-393.

5. Robson, B.J.; Hamilton, D.P.; Webstera, I.T.; Chan, T. Ten steps applied to development and evaluation of process-based biogeochemical models of estuaries. Environ. Model. Softw. 2008, 23, 369-384. [CrossRef]

6. Bennett, N.; Croke, B.F.W.; Jakeman, A.J.; Newham, L.T.H.; Norton, J.P. Performance evaluation of environmental models. In Proceedings of the 2010 International Congress on Environmental Modelling and Software, Ottawa, ON, Canada, 5-8 July 2010.

7. Jorgensen, S.E. Fundamentals of Ecological Modelling; Elsevier: Amsterdam, The Netherlands, 2001.

8. Wainwright, J.; Mulligan, M. Introduction in Environmental Modelling: Finding Simplicity in Complexity; John Wiley: Hoboken, NJ, USA, 2004.

9. Grafton, R.Q.; Nelson, H.W.; Turris, B. How to resolve the class ii common property problem? The case of british columbia's multi-species groundfish trawl fishery. In Proceedings of the Fisheries Economics and Management, Vancouver, BC, Canada, 5-6 August 2004.

10. Halliday, A.; Glaser, M. A management perspective on social ecological systems: A generic system model and its application to a case study from Peru. Hum. Ecol. Rev. 2011, 18, 1-18.

11. Alliance, R. Assessing and Managing Resilience in Social-Ecological Systems: A Practitioner's Workbook (Volume 1, Version 1.0). Available online: http://www.resalliance.org/3871.php (accessed on 8 January 2016).

12. Ostrom, E. Governing the Commons: The Evolution of Institutions for Collective Action; Cambridge University Press: New York, NY, USA, 1990.

13. Ostrom, E. A general framework for analyzing sustainability of socialecological systems. Science 2009, 325, 419-422. [CrossRef] [PubMed]

14. Ling, G.H.T.; Ho, C.S.; Ali, H.M.; Fan, T. Do institutions matter in neighbourhood commons governance? A two-stage relationship between diverse property-rights structure and residential public open space (pos) quality: Kota kinabalu and penampang, Sabah, Malaysia. Int. J. Commons 2016, 10, 294-333.

15. Ling, G.H.T. Institutional Property Rights of Residential Public Open Space in Sabah, Malaysia; Open Access; Universiti Teknologi Malaysia: Johor Bahru, Malaysia, 2017.

16. Sabahland, F. What Rights Do You Have When Purchasing Property in Sabah with a Loan. Available online: http:/ / www.sabahlaw.com/FAQsabahland.html (accessed on 20 November 2014).

17. Gerber, J.-D.; Knoepfel, P.; Nahrath, S.; Varone, F. Institutional resource regimes: Towards sustainability through the combination of propertyrights theory and policy analysis. Ecol. Econ. 2009, 68, 798-809. [CrossRef]

18. Ling, G.H.T.; Ali, N.E.; Ho, C.S.; Ali, H.M. Ostrom's design principles in residential public open space governance: Conceptual framework and literature review. Int. J. Built Environ. Sustain. 2014, 1. [CrossRef]

19. Ling, G.H.T.; Chau, L.W.; Ho, C.S.; Ali, H.M. Low-carbon ability of neighbourhood public open space (pos) governance: Explanation from social-ecological system and new institutional economics. Chem. Eng. Trans. 2018, 63, 469-474.

20. Strauss, A.; Corbin, J. Basics of Qualitative Research: Techniques and Procedures for Developing Grounded Theory, 2nd ed.; SAGE Publications, Inc.: Thousand Oaks, CA, USA, 1998.

21. Munasinghe, M. Environmental Economics and Sustainable Development; World Bank: Washington, DC, USA, 1992. 
22. Creswell, J.W.; Plano Clark, V.L. Designing and Conducting Mixed Methods Research; SAGE: Thousand Oaks, CA, USA, 2007.

23. Hair, J.; Anderson, R.E.; Tatham, R.L.; Black, W.C. Multivariate Data Analysis, 4th ed.; Prentice-Hall Inc.: Upper Saddle River, NJ, USA, 1995.

24. Kaczynski, A.T.; Stanis, S.A.; Besenyi, G.M. Development and testing of a community stakeholder park audit tool. Am. J. Prev. Med. 2012, 42, 242-249. [CrossRef] [PubMed]

25. Kaiser, H.F. An index of factorial simplicity. Psychometrika 1974, 39, 31-36. [CrossRef]

26. Denzin, N. The Research Act: A Theoretical Introduction to Sociological Methods; McGraw-Hill: New York, NY, USA, 1978.

27. Arhonditsis, G.B.; Brett, M.T. Evaluation of the current state of mechanistic aquatic biogeochemical modeling. Where are we? Mar. Ecol. Prog. Ser. 2004, 271, 13-26. [CrossRef]

28. Fulton, E.A.; Parslow, J.S.; Smith, A.D.M.; Johnson, C.R. Biogeochemical marine ecosystem models: The effect of physiological detail on model performance. Ecol. Model. 2004, 173, 371-406. [CrossRef]

29. O'Keefe, R.M.; O'Leary, D.E. Expert system verification and validation: A survey and tutorial. Artif. Intell. Rev. 1993, 7, 3-42. [CrossRef]

30. Walker, W.E.; Harremoes, P.; Rotmans, J.; Van der Sluijs, J.P.; Van Asselt, M.B.A.; Janssen, P.; Krayer von Krauss, M.P. Defining uncertainty: A conceptual basis for uncertainty management in model-based decision support. Integr. Assess. 2003, 4, 5-18. [CrossRef]

31. Bockstaller, C.; Girardin, P. How to validate environmental indicators? Agric. Syst. 2003, 76, 639-653. [CrossRef]

32. Aspinall, W. Structured elicitation of expert judgment for probabilistic hazard and risk assessment in volcanic eruptions. In Statistics in Volcanology; Mader, H.M., Coles, S.G., Connor, C.B., Connor, L.J., Eds.; Geological Society for IAVCEI: London, UK, 2006; pp. 15-30.

33. Creswell, J.W. Qualitative Inquiry and Research Design: Choosing among Five Approaches, 3rd ed.; SAGE: Thousand Oaks, CA, USA, 2013.

34. Creswell, J.W.; Miller, D.L. Determining validity in qualitative inquiry. Theory Pract. 2000, 39, $124-131$. [CrossRef]

35. Lincoln, Y.S.; Guba, E.G. Naturalistic Inquiry; SAGE: Beverly Hills, CA, USA, 1985.

36. Parker, P.; Letcher, R.; Jakeman, A.J.; Beck, M.B.; Harris, G.; Argent, R.M.; Hare, M.; Pahl-Wostl, C.; Voinov, A.; Janssen, M.; et al. Progress in integrated assessment and modeling. Environ. Model. Softw. 2002, 7, 209-217. [CrossRef]

37. Pidd, M. Tools for Thinking: Modelling in Management Science, 2nd ed.; Wiley: Chichester, UK, 2003.

38. Musole, M. Property rights, transaction costs and institutional change: Conceptual framework and literature review. Prog. Plan. 2009, 71, 43-85. [CrossRef]

39. Webster, C.J.; Lai, L.W.C. Property Rights, Planning and Markets: Managing Spontaneous Cities; Edward Elgar: Cheltenham, UK; Northampton, MA, USA, 2003.

(C) 2018 by the authors. Licensee MDPI, Basel, Switzerland. This article is an open access article distributed under the terms and conditions of the Creative Commons Attribution (CC BY) license (http:/ / creativecommons.org/licenses/by/4.0/). 